Int. J. Electrochem. Sci., 16 (2021) Article ID: 210834

International Journal of

ELECTROCHEMICAL

SCIENCE

$\underline{\text { www.electrochemsci.org }}$

\title{
Square-Wave Potential-Modified Pt Particles for Methanol and Ammonia Oxidation
}

\author{
Wenjie Fu $u^{1}$, Bin Liu ${ }^{1}$, Jie Liu ${ }^{1}$, Xiaopeng Han ${ }^{1,2}$, Yida Deng ${ }^{1,2}$, Cheng Zhong ${ }^{1,2,3, *}$ and Wenbin Hu ${ }^{1,2,3}$ \\ ${ }^{1}$ Key Laboratory of Advanced Ceramics and Machining Technology (Ministry of Education), School \\ of Materials Science and Engineering, Tianjin University, Tianjin 300072, China. \\ ${ }^{2}$ Tianjin Key Laboratory of Composite and Functional Materials, School of Materials Science and \\ Engineering, Tianjin University, Tianjin 300072, China. \\ ${ }^{3}$ Joint School of National University of Singapore and Tianjin University, International Campus of \\ Tianjin University, Binhai New City, Fuzhou 350207, China. \\ *E-mail: cheng.zhong@ tju.edu.cn
}

doi: $10.20964 / 2021.08 .02$

Received: 16 April 2021 / Accepted: 22 May 2021 / Published: 30 June 2021

\begin{abstract}
Platinum (Pt) particle electrocatalysts prepared by electrolytic deposition and periodic square-wave potential (PSWP) modification provide a promising alternative catalyst for the oxidation of ammonia and methanol. The whole electrochemical process avoided use the capping agent to ensure the high purity of the Pt catalyst. Dendritic and cube-like Pt particles were prepared in this work and the influences of the PSWP parameters (frequency $(f)$, time $(t)$, upper potential $\left(E_{\mathrm{U}}\right)$, lower potential $\left(E_{\mathrm{L}}\right)$ ) on the morphologies of the Pt particles were investigated. Based on the experimental results, a lower $f$ and a longer $t$ lead to the dendritic morphology of the Pt particles. A higher $E_{\mathrm{U}}$ and a lower $E_{\mathrm{L}}$ are more likely to convert the Pt particles to a cube-like morphology. Interestingly, the modified Pt electrocatalyst with dendritic shape showed excellent electrocatalytic performance when performed on methanol and ammonia. Moreover, the mass-specific activity (MA) of dendritic Pt particles (Pts-Den) catalysis of methanol is approximately five times higher than that of the electrocatalysts before modification. This result can be explained by the large electrochemically active surface area (ECSA) and high electrocatalytic activity per unit area.
\end{abstract}

Keywords: Pt particles, methanol and ammonia oxidation, electrocatalysis, periodic square-wave potential

\section{FULL TEXT}

(C) 2021 The Authors. Published by ESG (www.electrochemsci.org). This article is an open access article distributed under the terms and conditions of the Creative Commons Attribution license (http://creativecommons.org/licenses/by/4.0/). 